\title{
Risk factors associated with Trypanosoma cruzi exposure in domestic dogs from a rural community in Panama
}

\author{
Azael Saldaña ${ }^{1,2}$, José E Calzada1,3, Vanessa Pineda1, Milixa Perea1', Chystrie Rigg1, \\ Kadir González' ${ }^{1}$ Ana Maria Santamaria', Nicole L Gottdenker ${ }^{4}$, Luis F Chaves ${ }^{5,6 /+}$
}

\footnotetext{
${ }^{1}$ Instituto Conmemorativo Gorgas de Estudios de Salud, Departamento de Parasitología, Ciudad de Panamá, República de Panamá 2Universidad de Panamá, Facultad de Medicina, Centro de Investigación y Diagnóstico de Enfermedades Parasitarias, Ciudad de Panamá, República de Panamá ${ }^{3}$ Universidad de Panamá, Facultad de Medicina Veterinaria, Ciudad de Panamá, República de Panamá ${ }^{4}$ University of Georgia, College of Veterinary Medicine, Department of Veterinary Pathology, Athens, GA, USA ${ }^{5}$ Nagasaki University, Institute of Tropical Medicine, Nagasaki, Japan ${ }^{6}$ Universidad Nacional, Escuela de Medicina Veterinaria, Programa de Investigación en Enfermedades Tropicales, Heredia, Costa Rica
}

Chagas disease, caused by Trypanosoma cruzi infection, is a zoonosis of humans, wild and domestic mammals, including dogs. In Panama, the main T. cruzi vector is Rhodnius pallescens, a triatomine bug whose main natural habitat is the royal palm, Attalea butyracea. In this paper, we present results from three T. cruzi serological tests (immunochromatographic dipstick, indirect immunofluorescence and ELISA) performed in 51 dogs from 24 houses in Trinidad de Las Minas, western Panama. We found that nine dogs were seropositive (17.6\% prevalence). Dogs were 1.6 times more likely to become T. cruzi seropositive with each year of age and 11.6 times if royal palms where present in the peridomiciliary area of the dog's household or its two nearest neighbours. Mouse-baited-adhesive traps were employed to evaluate 12 peridomestic royal palms. All palms were found infested with R. pallescens with an average of 25.50 triatomines captured per palm. Of 35 adult bugs analysed, $88.6 \%$ showed protozoa flagellates in their intestinal contents. In addition, dogs were five times more likely to be infected by the presence of an additional domestic animal species in the dog's peridomiciliary environment. Our results suggest that interventions focused on royal palms might reduce the exposure to T. cruzi infection.

Key words: Trypanosoma cruzi - Canis familiaris - Rhodnius pallescens - Attalea butyracea - Chagas disease - Panama

Chagas disease, a parasitic infection caused by Trypanosoma cruzi, has a predominantly enzootic cycle in Panama (Whitlaw \& Chaniotis 1978). In most cases, human infection occurs when sylvatic infected vectors are attracted to lights, food sources or other factors related to human dwellings (Romaña et al. 2003). This transmission scenario differs from that reported in some Central and South American countries, where vectors colonise human dwellings and where domestic mammals, including dogs, are important T. cruzi reservoirs (Moncayo \& Silveira 2009, Esch \& Petersen 2013, Castillo-Neyra et al. 2015). Numerous studies have found domestic dogs infected with $T$. cruzi across endemic areas ranging from southern United States of America to Argentina (Gürtler et al. 2007). The reported prevalence varies widely (1.42-92\%), depending on ecoepidemiological and sociocultural factors (Crisante et al. 2006, Estrada-

doi: 10.1590/0074-02760150284

Financial support: SENACYT (CCP06-040, COL11-043),

Netropica (04-N-2010)

This paper also benefited from discussions held at a NIMBIOS

Investigative Workshop on Malaria-Leishmania Co-infections. AS

and JEC are members of the SNI-SENACYT, Panama.

+Corresponding author: 1chaves@nagasaki-u.ac.jp

Received 30 July 2015

Accepted 29 September 2015
Franco et al. 2006, Gürtler et al. 2007, Kjos et al. 2008, Romero-Peñuela \& Sánchez-Valencia 2008, BonfanteCabarcas et al. 2011, Manrique-Abril et al. 2012, Lizundia et al. 2014). Generally, canine infections are more prevalent than human infections, a fact likely related to oral $T$. cruzi transmission, a more efficient route of infection and apparently common to many mammals (Barretto et al. 1978, Roellig \& Yabsley 2010), and also the fact that dogs often sleep near houses and may come in greater contact with peridomiciliary vectors. Dogs are also considered natural sentinels (Castañera et al. 1998, Castillo-Neyra et al. 2015) and a biological barrier for human transmission (Pineda et al. 2011). In Panama, $T$. cruzi dog infection has also been reported in some active transmission areas (Romaña et al. 2003, Pineda et al. 2011, Fung et al. 2014). However, the prevalence of T. cruzi-infected dogs has not been studied in association with spatially explicit risk factors that could help to improve current, or to propose new control, measures. The objective of this study was to evaluate the exposure of dogs to T. cruzi infections in the rural community of Trinidad de Las Minas, Republic of Panama in relation to local and spatially explicit risk factors.

\section{MATERIALS AND METHODS}

Study site - We studied T. cruzi exposure in dogs from 24 households in Trinidad de Las Minas ( $8^{\circ} 46^{\prime} 32^{\prime \prime} \mathrm{N}$ $79^{\circ} 59^{\prime} 45^{\prime \prime} \mathrm{W}$ ), district of Capira, western Panama, a place where we have previously studied the epidemiology and control of cutaneous leishmaniasis (Saldaña et al. 2013). 
The 24 households were a clustered subset from 128 households in Trinidad de las Minas with similar ecoepidemiological conditions that were evaluated as part of a sandfly control trial using insecticide thermal fogging and where residents provided informed consent to monitor changes in sandfly abundance (Chaves et al. 2013), but also for the collection of blood samples from domestic animals (Calzada et al. 2015, González et al. 2015). In Trinidad de las Minas around $90 \%$ of the houses have dogs and 22 out of the 24 houses we studied had dogs. The district of Capira is generally considered endemic for Chagas disease; however no human seroprevalence studies have been conducted in the area of Trinidad de Las Minas. Climate in this community is unimodal, with a rainy (April-November) and dry (December-March) season. Monthly rain ranges from $28-570 \mathrm{~mm}^{3}$. Temperature is nearly constant with a year-round $26^{\circ} \mathrm{C}$ average. Characteristics of the study site were described in detail by Calzada et al. (2013).

Dog sampling - Inhabitants from 24 selected houses at Trinidad de Las Minas were asked the age and sex of each dog they owned. Dog age was confirmed by dentition and tartar deposition patterns (Calzada et al. 2015). A physical examination was performed and dogs were combed and visually inspected to evaluate ectoparasite infestation by fleas, lice or ticks. General body condition of each dog was assessed visually and by touch (spine and ribs) based on the scale developed by Baldwin et al. (2010). This information was also evaluated as a potential risk factor for exposure to T. cruzi when analysed in light of the results from the serological tests. Dogs were manipulated in the presence of their owners. Blood samples $(3 \mathrm{~mL})$ were obtained by puncture of the cephalic vein and collected into sterile serum tubes without anticoagulant. Two millilitres of blood were centrifuged. The serum fraction was collected for serological analysis and the remaining blood was resuspended with liver infusion tryptose medium and incubated at $27^{\circ} \mathrm{C}$, using the protocol presented by Vásquez et al. (1997). Cultures were checked weekly during two months for parasites presence. Serum from each dog was obtained by centrifugation at 2,000 rpm for $20 \mathrm{~min}$ and stored at $-20^{\circ} \mathrm{C}$ until use. Serum samples were analysed for anti- $T$. cruzi antibodies by a rapid test (Trypanosoma cruzi Detect ${ }^{\mathrm{TM}}$, InBios International Incorporated, USA), a partially modified commercial recombinant ELISA (ELISA Chagastest, Wiener lab, Argentina) using an anti-dog $\mathrm{IgG}$ peroxidase conjugated diluted 1:2000 (Sigma No A6792) and an indirect immunofluorescence antibody test (IFAT) with a local T. cruzi isolate (Burunga strain) as antigen. The first two tests are based on the use of recombinant antigens and, according to the manufacturers, these tests do not cross-react with other trypanosomatids, including Leishmania spp and Trypanosoma rangeli. The rapid test was carried out according to the manufacturer's instructions. It has a specificity of at least $94 \%$ and a sensitivity of at least $96 \%$ (Cardinal et al. 2006). The test was only considered positive when a second defined line besides the control line appeared on the test field. The intensity of the colour line was not interpreted in this study. For the ELISA, we replaced the anti-human $\operatorname{IgG}$ conjugate with an anti-dog $\operatorname{IgG}$ conjugate. We previously validated this ELISA kit with a panel of 10 positive and 10 negative canine sera from Chagas disease endemic areas in Panama. This test was optimised as follows: serum dilution (1:25), incubation time (30 min), dilution of anti-dog IgG conjugate (1:2000 Sigma No A6792) and signal development. For the IFAT, our controls also were positive and negative dog sera from Chagas disease endemic areas in Panama. The cutoff titre was 1:40, which was determined with a panel of 10 positive and 10 negative canine sera.

Ecological risk factors for exposure to T. cruzi - We collected information on potential ecological risk factors associated with canine Chagas disease. For each household we estimated: a housing destituteness index, which quantified how different elements of housing construction could render a house a suitable habitat for triatomine bugs (and insects in general), a peridomicile index, that quantified the presence of elements that could serve as refuge for triatomine bugs, for example palms and a vegetation index, that measured natural vegetation vertical structure, i.e., whether a site had many trees or was a pasture. We also quantified species richness, i.e., the number of species of domestic and wildlife mammals. In addition, we developed an index of domestic animal abundance which, based on a principal components analysis, weighted the abundance of different domestic species belonging to a household. Similarly, we developed an index for wild animal presence that weighted the commonness of different wildlife mammal species sighted by householders. A detailed description of data collection and the estimation of each index was presented by Chaves et al. (2013).

Since the dominant triatomine vector species in our study area is Rhodnius pallescens, a sylvatic species whose main natural habitat is the royal palm, Attalea butyracea (Pipkin 1968, Whitlaw \& Chaniotis 1978, Gottdenker et al. 2011), we also considered the presence of this palm species within the peridomicile (here defined as the area within a $50 \mathrm{~m}$ radius circumference around each household) of a focal household or in the peridomicile of any of the two households closest to the focal household. The $50 \mathrm{~m}$ radius was chosen to account for both sandfly and triatomine bug dispersal. For sandflies, dispersal distances rarely are over $50 \mathrm{~m}$ (Chaves et al. 2013) and field measurements recorded for Rhodnius prolixus (Gómez-Núñez 1969) suggest Rhodnius spp movement in peridomiciles unlikely exceeds $15 \mathrm{~m}$. Similarly, data for $R$. pallescens from flight mills has found median flight distances for adults of $50 \mathrm{~m}$ (Castro et al. 2014). The presence of triatomine bug palm infestation was determined using mouse-baited-adhesive traps, which can detect adults and nymphal instars (Noireau et al. 2002), three traps by palm for one night. The intestinal contents of all captured adults triatomines were analysed microscopically for the presence of flagellated protozoa.

Sensitivity and specificity for the serological tests indicative of T. cruzi exposure - Sensitivity, the accurate diagnosis of true infections and specificity, the proper 
diagnosis of lack of an infection, are generally assessed in the presence of a "gold standard" (Lalkhen \& McCluskey 2008), for example, the direct observation of a parasite or its DNA amplification via polymerase chain reaction (Altman \& Bland 1994). For Chagas disease (i.e., T. cruzi infections), due to the low parasitaemia observed in indeterminate and chronic infections, the Pan American Health Organization recommends the confirmation of the diagnosis by at least two serological methods (Carvalho et al. 1993), a criterion that we used as a gold standard to estimate sensitivity and specificity of the serological diagnostic tests following the steps described by Lalkhen and McCluskey (2008). We also estimated Cohen's kappa coefficient (Cohen 1960), a measurement of agreement between diagnostic tests, for all possible combinations of two serologic diagnostic methods and for all the diagnostic methods at once.

Risk factors for T. cruzi seropositive diagnostic - We first performed a household level analysis of risk factors associated with $T$. cruzi seropositive dogs, where dogs were assigned a seropositive status when they were positive by two or more diagnostic tests. For this purpose, we employed maximum likelihood Binomial Generalized Linear Models (Bin-GLMs) (Faraway 2006). In a first round of model selection we compared models with the same number of parameters, but with alternative risk factors. Briefly, all models included the housing destituteness index and the vegetation index, but considered the presence of domestic, which were censused by us and included dogs, cats, horses, chickens and parrots and wildlife animals, which were self-reported by householders and included sloths, opossums, porcupines, voles, bats, squirrels, monkeys and birds, by considering either their species richness or their abundance/presence indices. Similarly, we either considered the peridomiciliary index or palm presence in the peridomicile of a focal household or palm presence in either the focal household of the two closest neighbouring houses to a focal household. The best model selected in this first round was then further simplified employing a process of backward elimination (Faraway 2004). We selected T. cruzi seropositivity risk factors by using the Akaike Information Criterion (AIC), a criterion that both considers model likelihood and parameter number, because models were not nested during the first round of risk factor selection, i.e., not comparable via likelihood ratio tests since models did not shared the same variables (Venables \& Ripley 2002). Also, the alternative covariates we defined before are collinear, which can lead to problems in parameter estimation of linear models (Faraway 2004). Given the spatial nature of our data, we also tested the lack of spatial autocorrelation in the best model residuals, employing Moran's I test (Venables \& Ripley 2002). After the selection of relevant household risk factors for T. cruzi seropositive dogs, we performed an analysis considering information about potential individual based risk factors employing Logistic Generalized Estimating Equations Models (Log-GEEM). We employed Log-GEEM given the nature of the data, dogs belonging to the same household are not independent observations, a fact constrain- ing the use of regression tools that assume observation independence (Chaves 2010). We based our inferences on a sandwich estimator to obtain robust standard errors (SE), since naïve SEs are appropriate only when an appropriate correlation structure is specified (Faraway 2006). We thus assumed independence in the correlation structure of the model, given the robustness of GEEMs to provide reliable estimates using the robust SEs from the sandwich estimator (Venables \& Ripley 2002). We first specified a full model that included the best household level risk factors for T. cruzi seropositive dogs and the individual level factors that were variable in the dogs we studied. This model was simplified using a procedure similar to the one employed for the Bin-GLMs, but exclusively based on the quasi-likelihood information criterion (Pan 2001) the GEE analog to AIC.

Ethics - This study was evaluated and approved by the National Review Board, National Bioethics Committee of Research (CNBI), Gorgas Memorial Institute for Health Studies (ICGES), Panama (561/CNBI/ ICGES/06), and from ICGES Institutional Animal Care and Use Committee (2006/02). The study was in accordance with law No. 23 of 15 January 1997 (Animal Welfare Assurance) of Republic of Panama.

\section{RESULTS}

The 24 houses we surveyed (Fig. 1A) had 52 dogs, but we collected information and samples from 51, since one of the dogs was less than one month old and still weaning. All dogs were mixed breeds. The average ( \pm $\mathrm{SD})$ age of the dogs was $3.07 \pm 2.94$ years, 17 were females and 34 males. Most dogs (94\%) had ectoparasites (ticks and/or fleas) attached to their skin, $43 \%$ had a poor physical condition and 7\% slept inside the houses. Regarding $T$. cruzi infection, eight dogs were seropositive according to the rapid test, 10 by the modified ELISA and 10 by homemade IFAT. Nine dogs were considered seropositive by the composite gold standard (seropositivity in 2 or more tests), representing a seroprevalence of $17.6 \%$ (Fig. 1B). The spatial location of households where seropositive dogs were diagnosed by each test is depicted in Fig. 2. The sensitivity and specificity of the different serological tests are shown in Table I. The most sensitive and specific test was the Rapid test, followed by the IFAT and the modified ELISA. The inter-agreement between all diagnostic tests (Table II) was substantial according to the scale by Landis and Koch (1977) and between the paired tests, with the exception of the Rapid test - IFAT pair (Table II), whose value above 0.8 can be interpreted as an almost perfect agreement on T. cruzi serodiagnosis (Landis \& Koch 1977). Thus, in general, it can be affirmed that the diagnostic tests were in agreement on positive and negative diagnostics. None of the blood cultures were positive for hemoflagellates after two months of microscopic observation.

Royal palms were clustered around houses in the northern section of our study site (Fig. 1A), as were the greatest number of $T$. cruzi seropositive dogs positive by at least two diagnostic tests (Fig. 1B). Twelve palm trees were sampled for triatomine bugs in the perid- 

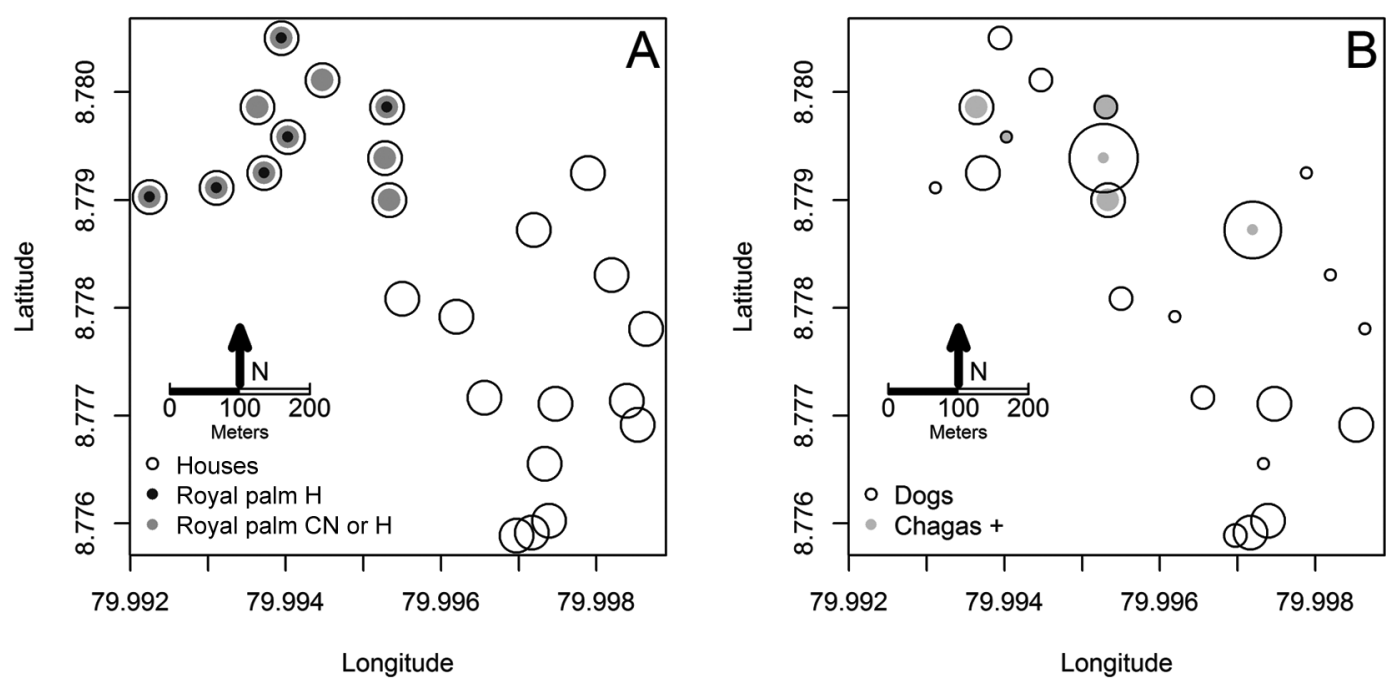

Fig. 1A: royal palms and Trypanosoma cruzi seropositive dogs; B: study houses indicating whether their peridomicile (area within a $50 \mathrm{~m}$ radius circumference around the house) or that of the two closest neighbouring houses had the royal palm Attalea butyracea. Number of T. cruzi seropositive dogs (based on positive diagnosis from at least 2 tests) and all dogs per household in this panel symbol size in the inset legend corresponds to one individual. $\mathrm{CN}$ : in the peridomicile of the two closest neighbouring houses; $\mathrm{H}$ : in the house peridomicile.

omicile areas of houses (and their closest neighbours) where dogs were seropositive. All of the palms had $R$. pallescens $(100 \%$ infestation index), with a capture rate of 8.5 triatomine/trap/night and an average $[ \pm$ standard deviation (SD)] of $25.50 \pm 14.26$ specimens captured per palm, specifically with $18.83 \pm 15.08$ nymphs/palm and $4.67 \pm 4.92$ adults/palm. Here, it is important to note that the low variability (measured by the SD) to mean ratio in triatomine bugs imply that they were uniformly distributed across the palms independently of their age, but randomly distributed regarding their age, where the ratio was close to one (Morisita 1962). Of 35 adult bugs captured, $31(88.6 \%)$ had protozoan flagellates in their intestinal contents during microscopic examination. The presence of palms in the peridomicile of a focal household or the peridomicile of any of its two closest neighbouring houses was a significant risk factor for a dog being T. cruzi seropositive at the household level (Table III). The other significant factor associated with $T$. cruzi seroprevalence patterns across the surveyed houses was the number of domestic animal species owned by a given house (Table III). At the household level, royal palm presence increased the odds of dogs being seropositive to $T$. cruzi by 11 times and each domestic mammal species in a household increased the likelihood of $T$. cruzi seropositivity in dogs belonging to that household by four times (Table IV). The residuals of the best model were spatially independent (Table IV), ensuring a statistically sound inference (Venables \& Ripley 2002). The only factors that were variable enough across the dogs we surveyed to be evaluated as risk factors in the population we studied were dog physical condition, age and sex. The simplification of a model considering these three factors, as well as the presence of royal palms in the peridomicile of the household (and/or the 2 closest neighbours) where a dog belonged and domestic animal species richness, showed that physical condition and sex were not important risk factors for T. cruzi seroprevalence (Table V). The best logistic generalised estimating equations model (Table VI) found that odds of an individual dog being T. cruzi seropositive increased 1.59 times with each year of age, 11.5 times when there are royal palms in the household (or 2 closest neighbouring households) and about five times by the presence of a domestic animal species other than a dog.

\section{DISCUSSION}

The role of domestic dogs in the epidemiology of Chagas disease has been studied extensively in communities where triatomine bugs colonise peridomestic and domestic environments (Castañera et al. 1998, Gürtler et al. 2007, Castillo-Neyra et al. 2015). Nevertheless, studies on dog infections with $T$. cruzi in communities where vectors sporadically invade houses from nearby biotopes, such as $R$. pallescens from palm trees, are relatively rare.

In this study, canine T. cruzi infection was confirmed in nine of $51(17.6 \%)$ evaluated dogs from the rural community of Trinidad Las Minas. This village is located in a mountainous region surrounded by abundant forest remnants, where $T$. cruzi animal reservoirs (González et al. 2015) and royal palms are common. This rural settlement has been recently identified as highly endemic for cutaneous leishmaniasis (Saldaña et al. 2013), a vector-borne parasitic disease also associated with tropical humid forests and with high seroprevalence (47\%) of Leishmania panamensis infection in dogs (Calzada et al. 2015).

Previous studies conducted in other communities located in western province of Panama have reported $T$. cruzi prevalence in domestic dogs as 37\% (Romaña et al. 2003), 11.1\% (Pineda et al. 2011) and 8.97\% (Fung et al. 
TABLE I

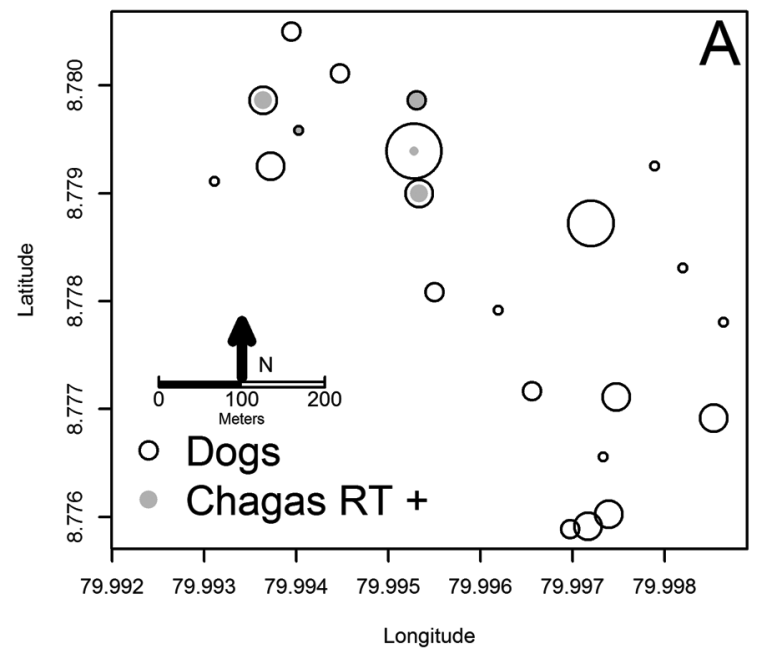

Sensitivity and specificity of serological diagnostic tests for

\begin{tabular}{lcc}
\multicolumn{3}{c}{ Trypanosoma cruzi exposure } \\
\hline Diagnostic test & $\begin{array}{c}\text { Sensitivity } \\
(\%)\end{array}$ & $\begin{array}{c}\text { Specificity } \\
(\%)\end{array}$ \\
\hline Rapid test & 100 & 98 \\
ELISA Winner & 80 & 95 \\
IFAT & 90 & 98
\end{tabular}

seropositivity was used by at least two tests as a gold standard. IFAT: immunofluorescence antibody test.

\section{TABLE II}

Kappa coefficient of agreement between the serological diagnostic tests for Trypanosoma cruzi exposure
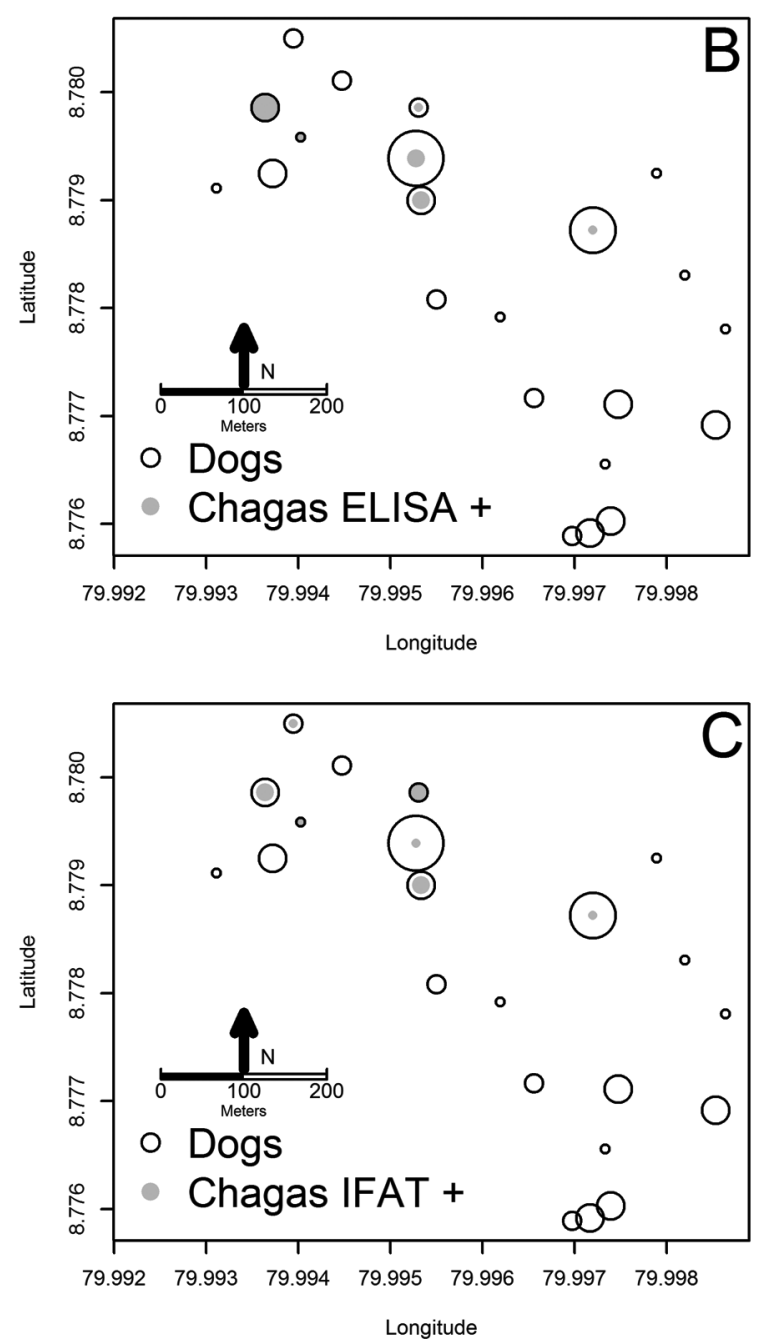

TABLE III

Model selection of risk factors for Trypanosoma cruzi seropositive reactions in dogs at the household level in Trinidad de Las Minas, western Republic of Panama

\begin{tabular}{lccc}
$\begin{array}{l}\text { Selection } \\
\text { round }\end{array}$ & Risk factors & AIC & $\Delta$ AIC \\
\hline $0^{a}$ & Palms + VI + HP + DAI + WPI & 37.10 & 11.37 \\
& PI + VI + HP + DAI + WPI & 35.72 & 9.99 \\
& PI + VI + HP + DSR + WSR & 33.28 & 7.55 \\
& Palms + VI + DI + DSR + WSR & 31.62 & 5.89 \\
& Npalms + VI + HP + DAI + WPI & 30.52 & 4.79 \\
& Npalms + VI + DI + DSR + WSR & 26.81 & 1.08 \\
$1^{b}$ & Npalms + DSR & $\mathbf{2 5 . 7 3}$ & --
\end{tabular}

$a$ : models with the same number of parameters, but alternative covariates; $b$ : final model from the stepwise backward elimination of selection round 0; AIC: Akaike Information Criterion; DAI: domestic animal abundance index; DSR: domestic animal species richness; HP: housing destituness; Npalms: palms in the peridomicile of the focal household and/or any of its two closest neighbours; Palms: palms in the peridomicile; PI: peridomicile index; VI: vegetation index; WPI: wild animal presence index; WSR: wildlife animal species richness; $\triangle \mathrm{AIC}$ : is the difference between each model AIC with that of the model with minimum AIC. The final best model (minimum AIC) is bolded.

Fig. 2: number of Trypanosoma cruzi seropositive dogs per household according to different diagnostic tests: rapid test (RT) (A) ELISA Winner (B) and immunofluorescence antibody test (IFAT) (C). Each panel also shows the total number of dogs per household. In each legend symbol size corresponds to two individuals.

\begin{tabular}{lccc}
\hline Diagnostic test & Kappa & $\mathrm{Z}$ & $\mathrm{p}$ \\
\hline Rapid test - ELISA Winner & 0.731 & 5.27 & $<0.00001^{a}$ \\
Rapid test - IFAT & 0.865 & 6.24 & $<0.00001^{a}$ \\
IFAT - ELISA Winner & 0.751 & 5.36 & $<0.00001^{a}$ \\
Rapid test - IFAT - ELISA Winner & 0.781 & 9.67 & $<0.00001^{a}$ \\
\hline : statistically significant $(\mathrm{p}<0.05)$; IFAT: immunofluores- \\
cence antibody test.
\end{tabular}




\section{TABLE IV}

Odds ratios (OR) and parameter estimates for the best binomial generalised linear model for risk factors associated with Trypanosoma cruzi seropositive reactions in domestic dogs at the household level in Trinidad de Las Minas, western Republic of Panama

\begin{tabular}{|c|c|c|c|c|c|}
\hline Parameter & $\begin{array}{c}\text { OR } \\
(95 \% \mathrm{CI})\end{array}$ & Estimate & $\mathrm{SE}$ & Z & $\mathrm{p}$ \\
\hline Intercept & 1 & -7.25 & 2.27 & -3.18 & $0.001^{a}$ \\
\hline Palms in focal household and/or two closest neighbouring houses & $11.22(1.56-236.60)$ & 2.42 & 1.17 & 2.06 & $0.039^{a}$ \\
\hline Domestic animal species richness & $3.97(1.41-16.99)$ & 1.38 & 0.61 & 2.26 & $0.024^{a}$ \\
\hline Moran's I of the residuals ${ }^{b}$ & - & -0.27 & - & - & 0.923 \\
\hline
\end{tabular}

$a$ : statistically significant $(\mathrm{p}<0.005)$; $b$ : the inference for the Moran's I is based on a MonteCarlo simulation; CI: confidence interval; SE: standard error.

\section{TABLE V}

Model selection for risk factors associated with Trypanosoma cruzi seropositive reactions in dogs from Trinidad de Las Minas, western Republic of Panama

\begin{tabular}{lccc}
\hline $\begin{array}{l}\text { Selection } \\
\text { round }\end{array}$ & Risk factors & QIC & $\Delta$ QIC \\
\hline $0^{a}$ & $\begin{array}{c}\text { Npalms + DSR }+ \\
\text { dog poor physical condition, } \\
\text { dog sex, dog age }\end{array}$ & 31.55 & 1.40 \\
1 & $\begin{array}{c}\text { Npalms + DSR }+ \\
\text { age }+ \text { sex }\end{array}$ & 30.76 & 0.61 \\
2 & Npalms + DSR + age & $\mathbf{3 0 . 1 5}$ & -
\end{tabular}

$a$ : full model; DSR: domestic animal species richness; Npalms: palms in the peridomicile of the focal household and/or any of its two closest neighbours; QIC: Pan's quasi-likelihood information criterion; $\triangle \mathrm{QIC}$ : difference between each model QIC with that of the model with minimum QIC. Best model is bolded.

2014). However, in these studies the association of infected dogs with spatially explicit risk factors for the transmission of T. cruzi infection was not assessed. Here we show that the odds of a dog being seropositive for T. cruzi increased 1.6 times with each year of age (Table IV). This tendency of increased age associated with $T$. cruzi seroprevalence has been previously reported in many settings in Latin America and could reflect cumulative exposure to parasitic infections (Estrada-Franco et al. 2006, Gürtler et al. 2007, Pineda et al. 2011), similar to the patterns observed for cutaneous leishmaniasis parasites at the study area (Calzada et al. 2015). Most dogs in the studied community of Trinidad de Las Minas are watchdogs that stay most of the time outside and/or around houses. In this peridomestic environment, dogs probably were exposed to $T$. cruzi by eating or chewing infected triatomine bugs from nearby royal palms. Dog infection due to ingestion or contact with infected wild reservoirs, such as opossums, is another possibility, although less likely. Thus, it is reasonable to believe that older dogs have had more exposure with these sources of infection.
No sex-related or body condition differences in the T. cruzi seropositive dogs was observed (Table V). However, it is important to consider that $43 \%$ of the evaluated dogs were in poor physical condition, a status that could lead to higher rates of $T$. cruzi infectivity to uninfected triatomine bugs that reach the houses (Petersen et al. 2001). Nevertheless, a high percentage (88.6\%) of adult triatomines collected on the evaluated royal palms was already infected with trypanosomatids. A similar result was confirmed by molecular techniques in another endemic neighbouring district, where $72.7 \%$ of $R$. pallescens entering houses were infected with $T$. cruzi (Calzada et al. 2006). Additionally, we did not find dogs able to generate positive T. cruzi blood cultures, suggesting that parasitaemia of the evaluated seropositive dogs was low, most probably because seropositive dogs were chronically infected. The low sensitivity of blood cultures and molecular methods for detecting T. cruzi infections during the human chronic phase has been previously reported in Panama (Sousa 1972, Calzada et al. 2006, Garisto-Risco et al. 2009). During physical exams, no evident symptoms of acute Chagas disease were observed in the evaluated dogs. Although acute Chagas disease cases in dogs are rarely reported in Panama, we have observed sporadic fatal cases from suburban areas in western Panama (Samudio et al. 2007). Trinidad de Las Minas is a rural and poor community where no veterinary services are available and no regular surveillance or preventive measures for dog diseases are undertaken by local authorities. Generally, the microclimatic conditions of temperature and humidity needed for $R$. pallescens survival for several weeks are not present in human dwellings. This observation is confirmed by the inability of this species to successfully colonise houses (Calzada et al. 2006, Hurtado et al. 2014). These considerations suggest that domestic dogs play a limited role in the spread of $T$. cruzi in endemic areas of Panama where $R$. pallescens is the main vector. However, dogs can be suitable sentinels for $T$. cruzi epidemiological surveillance in Chagas disease endemic areas (Castañera et al. 1998, Castillo-Neyra et al. 2015), given the easiness to measure infection exposure through serological tests.

In addition, dogs living in households near royal palms had an 11-fold increased odds of T. cruzi seroposi- 


\section{TABLE VI}

Odds ratios (OR) and parameter estimates for the best logistic generalised estimating equations model for risk factors associated with Trypanosoma cruzi seropositive reactions in domestic dogs from Trinidad de Las Minas, western Republic of Panama

\begin{tabular}{lcccccc}
\hline \multirow{2}{*}{ Parameter } & & & Naïve & Naïve & \multicolumn{2}{c}{ Sandwich Sandwich } \\
& OR & Estimate & SE & Z & SE & Z \\
\hline Intercept & - & -9.890 & 2.680 & -3.690 & 3.281 & -3.014 \\
Age & 1.586 & 0.461 & 0.170 & 2.715 & 0.188 & 2.454 \\
Palms in focal household and/or two closest neighbouring houses & 11.594 & 2.450 & 1.085 & 2.259 & 0.957 & 2.561 \\
Domestic animal species richness & 4.978 & 1.605 & 0.620 & 2.587 & 0.792 & 2.027 \\
\hline
\end{tabular}

SE: standard error.

tivity (Table IV). Infestation of palm trees by triatomines has been considered a risk factor for the transmission of Chagas disease in Panama and other regions of South America (Whitlaw \& Chaniotis 1978, Romaña et al. 2003, Lima et al. 2008, Angulo et al. 2012, Ricardo-Silva et al. 2012, Hurtado et al. 2014). Royal palms are abundant in the community of Trinidad de Las Minas, yet in the subset of houses we studied, they were clustered towards the north. The entomological evaluation conducted during this study showed that all the palms near the evaluated houses were infested with $R$. pallescens. Also, results from our palm sampling showed that palms can contain many triatomines. In this sense, it is important to mention that during the development of this study, three $R$. pallescens adults were found in houses by homeowners. As suggested in a related study from this region of Panama (Hurtado et al. 2014), Chagas disease control requires the implementation of specific interventions for reducing or eliminating $R$. pallescens populations established on royal palms from peridomestic areas.

Finally, we found that dogs were about five times more likely to be $T$. cruzi seropositive with each domestic animal species present in the household peridomicile in addition to dogs, suggesting that the presence of increased numbers of domestic animal species increase the infection risk, unlike predictions of a "dilution effect" where transmission is expected to decrease with species richness (Keesing et al. 2006). This scenario can be partially explained by an increase in the arrival/activity of triatomines attracted by additional sources for bloodmeals in the peridomestic environment (Rabinovich et al. 2011). In addition, the abundance and richness of domestic animals was positively associated. Thus, the presence of less frequent domestic animals, i.e., horses, cats and parrots, was associated with a larger abundance of dogs and chickens, which might indicate domestic animal abundance, played a role in shaping $T$. cruzi risk exposure patterns. In a recent study, the epidemiological role of domestic animals, especially chickens, was associated with an increased risk of transmission for Chagas infection in competent hosts, even though chickens themselves are not competent hosts for T. cruzi (Gürtler et al. 2014). Similar patterns where the "dilution effect" was not observed at the local scale of transmission have been reported for West Nile virus (Loss et al. 2009) and further highlight the role that blood foraging and host accessibility might have on the potential association between host biodiversity and pathogen transmission (Chaves et al. 2007, 2010, Rabinovich et al. 2011).

We must stress that our results are focused on T. cru$z i$-infected dogs and that it is still necessary to determine if similar risk factors are important for humans. In this sense, the presence of T. cruzi in dogs at Trinidad de Las Minas raises awareness regarding the potential for human transmission of this parasite in this village that also has high cutaneous leishmaniasis infection prevalence (Saldaña et al. 2013). It is therefore important that health authorities carry out necessary activities to determine the prevalence, management and prevention of Chagas infection among their inhabitants as well as in other nearby communities with similar ecoepidemiological features.

\section{ACKNOWLEDGEMENTS}

To the dog owners, for participation and cooperation, to José Montenegro, Fausto Martinez and Roberto Rojas, for field and technical assistance, and to Miss Junko Sakemoto, for providing administrative support at Nagasaki University.

\section{REFERENCES}

Altman D, Bland J 1994. Statistics notes: diagnostic tests I: sensitivity and specificity. BMJ 308: 1552.

Angulo VM, Esteban L, Luna KP 2012. Attalea butyracea próximas a las viviendas como posible fuente de infestación domiciliaria por Rhodnius prolixus (Hemiptera: Reduviidae) en los Llanos Orientales de Colombia. Biomedica 32: 277-285.

Baldwin K, Bartges J, Buffington T, Freeman LM, Grabow M, Legred J, Ostwald D 2010. AAHA nutritional assessment guidelines for dogs and cats. J Am Anim Hosp Assoc 46: 285-296.

Barretto MP, Ribeiro RD, Belda Neto FM 1978. Reservoirs and wild vectors of Trypanosoma cruzi. LXVIII: infection of mammals by oral route. Rev Bras Biol 38: 455-459.

Bonfante-Cabarcas R, Rodríguez-Bonfante C, Vielma BO, García D, Saldivia AM, Aldana E, Curvelo JL 2011. Seroprevalencia de la infección por Trypanosoma cruzi y factores asociados en un área endémica de Venezuela. Cad Saude Publica 27: 1917-1929.

Calzada JE, Pineda V, Montalvo E, Alvarez D, Santamaría AM, Samudio F, Bayard V, Cáceres L, Saldaña A 2006. Human trypanosome infection and the presence of intradomicile Rhodnius pallescens in the western border of the Panama Canal, Panama. Am J Trop Med Hyg 74: 762-765. 
Calzada JE, Saldaña A, González K, Rigg C, Pineda V, Santamaría AM, Rodríguez I, Gottdenker NL, Laurenti MD, Chaves LF 2015. Cutaneous leishmaniasis in dogs: is high seroprevalence indicative of a reservoir role? Parasitology 142: 1202-1214.

Calzada JE, Saldaña A, Rigg C, Valderrama A, Romero L, Chaves LF 2013. Changes in phlebotomine sand fly species composition following insecticide thermal fogging in a rural setting of western Panama. PLOS ONE 8: e53289.

Cardinal MV, Reithinger R, Gürtler RE 2006. Use of an immunochromatographic dipstick test for rapid detection of Trypanosoma cruzi in sera from animal reservoir hosts. J Clin Microbiol 44: 3005-3007.

Carvalho MR, Krieger MA, Almeida E, Oelemann W, Shikanai-Yassuda MA, Ferreira AW, Pereira JB, Sáez-Alquézar A, Dorlhiac-Llacer PE, Chamone DF 1993. Chagas disease diagnosis: evaluation of several tests in blood bank screening. Transfusion 33: 830-834.

Castañera MB, Lauricella MA, Chuit R, Gürtler RE 1998. Evaluation of dogs as sentinels of the transmission of Trypanosoma cruzi in a rural area of north-western Argentina. Ann Trop Med Parasitol 92: 671-683.

Castillo-Neyra R, Chu LC, Quispe-Machaca V, Ancca-Juarez J, Chavez FSM, Mazuelos MB, Naquira C, Bern C, Gilman RH, Levy MZ 2015. The potential of canine sentinels for reemerging Trypanosoma cruzi transmission. Prev Vet Med 120: 349-356.

Castro LA, Peterson JK, Saldaña A, Perea MY, Calzada JE, Pineda V, Dobson AP, Gottdenker NL 2014. Flight behavior and performance of Rhodnius pallescens (Hemiptera: Reduviidae) on a tethered flight mill. J Med Entomol 51: 1010-1018.

Chaves LF 2010. An entomologist guide to demystify pseudoreplication: data analysis of field studies with design constraints. $J$ Med Entomol 47: 291-298.

Chaves LF, Calzada JE, Rigg C, Valderrama A, Gottdenker NL, Saldaña A 2013. Leishmaniasis sand fly vector density reduction is less marked in destitute housing after insecticide thermal fogging. Parasit Vectors 6: 164.

Chaves LF, Harrington LC, Keogh CL, Nguyen AM, Kitron UD 2010. Blood feeding patterns of mosquitoes: random or structured? Front Zool 7: 3.

Chaves LF, Hernandez M-J, Dobson AP, Pascual M 2007. Sources and sinks: revisiting the criteria for identifying reservoirs for American cutaneous leishmaniasis. Trends Parasitol 23: 311-316.

Cohen J 1960. A coefficient of agreement for nominal scales. Educ Psychol Meas 20: 37-46.

Crisante G, Rojas A, Teixeira MM, Añez N 2006. Infected dogs as a risk factor in the transmission of human Trypanosoma cruzi infection in western Venezuela. Acta Trop 98: 247-254.

Esch KJ, Petersen CA 2013. Transmission and epidemiology of zoonotic protozoal diseases of companion animals. Clin Microbiol Rev 26: 58-85.

Estrada-Franco JG, Bhatia V, Diaz-Albiter H, Ochoa-Garcia L, Barbabosa A, Vazquez-Chagoyan JC, Martinez-Perez MA, GuzmanBracho C, Garg N 2006. Human Trypanosoma cruzi infection and seropositivity in dogs, Mexico. Emerg Infect Dis 12: 624-630.

Faraway J 2004. Linear models with R, CRC Press, Boca Raton, 274 pp.

Faraway J 2006. Extending the linear model with R: generalized linear, mixed effects and nonparametric regression models, Chapman \& Hall/CRC Press, Boca Raton, 331 pp.

Fung HL, Calzada J, Saldaña A, Santamaria AM, Pineda V, Gonzalez K, Chaves LF, Garner B, Gottdenker N 2014. Domestic dog health worsens with socio-economic deprivation of their home communities. Acta Trop 135: 67-74.
Garisto-Risco JD, Saldaña A, Zebede S, Calzada JE 2009. Cardiac disease in seropositive chagasic patients in Panama. Rev Esp Cardiol 62: 947-948.

Gómez-Núñez JG 1969. Resting places, dispersal and survival of Co60-tagged adult Rhodnius prolixus. J Med Entomol 6: 83-86.

González K, Calzada JE, Saldaña A, Rigg C, Alvarado G, RodríguezHerrera B, Kitron UD, Adler GH, Gottdenker NL, Chaves LF, Baldi M 2015. Survey of wild mammal hosts of cutaneous leishmaniasis parasites in Panama and Costa Rica. Trop Med Health 43: 75-78.

Gottdenker NL, Calzada JE, Saldaña A, Carroll CR 2011. Association of anthropogenic land use change and increased abundance of the Chagas disease vector Rhodnius pallescens in a rural landscape of Panama. Am J Trop Med Hyg 84: 70-77.

Gürtler RE, Cecere MC, Lauricella MA, Cardinal MV, Kitron U, Cohen JE 2007. Domestic dogs and cats as sources of Trypanosoma cruzi infection in rural northwestern Argentina. Parasitology 134: 69-82.

Gürtler RE, Cecere MC, Vázquez-Prokopec GM, Ceballos L, Gurevitz JM, Fernández MDP, Kitron U, Cohen JE 2014. Domestic animal hosts strongly influence human-feeding rates of the Chagas disease vector Triatoma infestans in Argentina. PLoS Negl Trop Dis 8: e2894.

Hurtado L, Calzada JE, Pineda V, González K, Santamaría AM, Cáceres L, Wald C, Saldaña A 2014. Conocimientos y factores de riesgo relacionados con la enfermedad de Chagas en dos comunidades panameñas donde Rhodnius pallescens es el vector principal. Biomedica 34: 260-270.

Keesing F, Holt RD, Ostfeld RS 2006. Effects of species diversity on disease risk. Ecol Lett 9: 485-498.

Kjos SA, Snowden KF, Craig TM, Lewis B, Ronald N, Olson JK 2008. Distribution and characterization of canine Chagas disease in Texas. Vet Parasitol 152: 249-256.

Lalkhen AG, McCluskey A 2008. Clinical tests: sensitivity and specificity. Contin Educ Anaesth Crit Care Pain 8: 221-223.

Landis JR, Koch G 1977. The measurement of observer agreement for categorical data. Biometrics 33: 159-174.

Lima MM, Coutinho CFS, Gomes TF, Oliveira TG, Duarte R, Borges-Pereira J, Bóia MN, Sarquis O 2008. Risk presented by Copernicia prunifera palm trees in the Rhodnius nasutus distribution in a Chagas disease-endemic area of the Brazilian Northeast. Am J Trop Med Hyg 79: 750-754.

Lizundia R, Picado A, Cordero M, Calderón A, Deborggraeve S, Montenegro VM, Urbina A 2014. Molecular and serological rapid tests as markers of Trypanosoma cruzi infection in dogs in Costa Rica. Trop Parasitol 4: 111-114.

Loss SR, Hamer GL, Walker ED, Ruiz MO, Goldberg TL, Kitron UD, Brawn JD 2009. Avian host community structure and prevalence of West Nile virus in Chicago, Illinois. Oecologia 159: 415-424.

Manrique-Abril D, Manrique-Abril F, Lorca M, Ospina J 2012. Prevalencia de anticuerpos para Trypanosoma cruzi en caninos de dos municipios endémicos de Boyacá. Rev MVZ Cordoba 17: 2916-2923.

Moncayo A, Silveira AC 2009. Current epidemiological trends for Chagas disease in Latin America and future challenges in epidemiology, surveillance and health policy. Mem Inst Oswaldo Cruz 104 (Suppl. I): 17-30.

Morisita M 1962. $I_{d}$-index, a measure of dispersion of individuals. Res Popul Ecol 4: 1-7.

Noireau F, Abad-Franch F, Valente SAS, Dias-Lima A, Lopes CM, Cunha V, Valente VC, Palomeque FS, de Carvalho-Pinto CJ, Sherlock I, Aguilar M, Steindel M, Grisard EC, Jurberg J 2002. Trapping Triatominae in silvatic habitats. Mem Inst Oswaldo Cruz 97: 61-63. 
Pan W 2001. Akaike's information criterion in generalized estimating equations. Biometrics 57: 120-125.

Petersen RM, Gürtler RE, Cecere MC, Rubel DN, Lauricella MA, Hansen D, Carlomagno MA 2001. Association between nutritional indicators and infectivity of dogs seroreactive for Trypanosoma cruzi in a rural area of northwestern Argentina. Parasitol Res 87: 208-214.

Pineda V, Saldaña A, Monfante I, Santamaría AM, Gottdenker NL, Yabsley MJ, Rapoport G, Calzada JE 2011. Prevalence of trypanosome infections in dogs from Chagas disease endemic regions in Panama, Central America. Vet Parasitol 178: 360-363.

Pipkin AC 1968. Domiciliary reduviid bugs and the epidemiology of Chagas disease in Panama (Hemiptera: Reduviidae: Triatominae). J Med Entomol 5: 107-124.

Rabinovich JE, Kitron UD, Obed Y, Yoshioka M, Gottdenker N, Chaves LF 2011. Ecological patterns of blood-feeding by kissing-bugs (Hemiptera: Reduviidae: Triatominae). Mem Inst Oswaldo Cruz 106: 479-494.

Ricardo-Silva AH, Lopes CM, Ramos LB, Marques WA, Mello CB, Duarte R, de la Fuente ALC, Toma HK, Reboredo-Oliveira L, Kikuchi SA, Baptista TF, Santos-Mallet JR, Junqueira ACV, Gonçalves TCM 2012. Correlation between populations of Rhodnius and presence of palm trees as risk factors for the emergence of Chagas disease in Amazon Region, Brazil. Acta Trop 123: 217-223.

Roellig DM, Yabsley MJ 2010. Infectivity, pathogenicity and virulence of Trypanosoma cruzi isolates from sylvatic animals and vectors and domestic dogs from the United States in ICR strain mice and SD strain rats. Am J Trop Med Hyg 83: 519-522.
Romaña CA, Brunstein D, Collin-Delavaud A, Sousa O, Ortega-Barría E 2003. Public policies of development in Latin America and Chagas disease. Lancet 362: 579.

Romero-Peñuela MH, Sánchez-Valencia JA 2008. Seroprevalencia de Trypanosoma cruzi por la técnica de western blot en población canina del departamento del Tolima, Colombia. Vet Zootec 2: 48-52.

Saldaña A, Chaves LF, Rigg CA, Wald C, Smucker JE, Calzada JE 2013. Clinical cutaneous leishmaniasis rates are associated with household Lutzomyia gomezi, Lu. panamensis and Lu. trapidoi abundance in Trinidad de Las Minas, western Panama. Am J Trop Med Hyg 88: 572-574.

Samudio F, Ortega-Barría E, Saldaña A, Calzada J 2007. Predominance of Trypanosoma cruzi I among Panamanian sylvatic isolates. Acta Trop 101: 178-181.

Sousa OE 1972. Notes on Chagas disease in Panama. Incidence and distribution of Trypanosoma cruzi and Trypanosoma rangeli. Rev Biol Trop 20: 167-169.

Vásquez JE, Krusnell J, Orn A, Sousa OE, Harris RA 1997. Serological diagnosis of Trypanosoma rangeli infected patients. A comparison of different methods and its implications for the diagnosis of Chagas disease. Scand J Immunol 45: 322-330.

Venables WN, Ripley BD 2002. Modern applied statistics with S, Springer, New York, 495 pp.

Whitlaw JT, Chaniotis BN 1978. Palm trees and Chagas disease in Panama. Am J Trop Med Hyg 27: 873-881. 